Cell Research (2000), 10, 213-220

\title{
Effect of Bcl-2 and caspase-3 on calcium distribution in apoptosis of $\mathrm{HL}-60$ cell
}

\author{
Zhang Min, Hong Qing Zhang, Shao Bai Xue* \\ Department of Biology, Beijing Normal University, Beijing \\ 100875, China
}

\begin{abstract}
Apoptosis manifests in two major execution programs downstream of the death signal: the caspase pathway and organelle dysfunction. An important antiapoptosis factor, Bcl-2 protein, contributes in caspase pathway of apoptosis. Calcium, an important intracellular signal element in cells, is also observed to have changes during apoptosis, which maybe affected by Bcl-2 protein. We have previously reported that in Harringtonine (HT) induced apoptosis of HL-60 cells, there's a change of intracellular calcium distribution, moving from cytoplast especially Golgi's apparatus to nucleus and accumulating there with the highest concentration. We report here that caspase- 3 becomes activated in HT-induced apoptosis of HL-60 cells, which can be inhibited by overexpression of Bcl-2 protein. No sign of apoptosis or intracellular calcium movement from Golgi's apparatus to nucleus in HL-60 cells overexpressing Bcl-2 or treated with Ac-DEVD-CHO, a specific inhibitor of caspase-3. The results indicate that activated caspase-3 can promote the movement of intracellular calcium from Golgi' s apparatus to nucleus, and the process is inhibited by Ac-DEVD-CHO (inhibitor of caspase-3), and that Bcl-2 can inhibit the movement and accumulation of intracellular calcium in nucleus through its inhibition on caspase-3. Calcium relocalization in apoptosis seems to be irreversible, which is different from the intracellular calcium changes caused by growth factor.
\end{abstract}

Key words: Apoptosis, calcium, caspase-3, bcl-2, laser scanning confocal microscopy (LSCM).

* Corresponding author. Tel: +86 10 62208196; E-mail: xuesb@bnu.edu.cn 
Effect of Bcl-2 and caspase-3 on calcium distribution in apoptosis of HL-60 cell

\section{INTRODUCTION}

Apoptosis is a kind of cell death that is executed through a suicide program[1], which is characterized by a variety of morphological and biochemical events, including chromatin condensation, fragmentation of DNA, blebbing of the plasma membrane, and PS externalization[2]. Genetic analysis of apoptosis in Caenorhabditis elegans started researches on the mechanism of apoptosis and found three most important genes are ced-3, ced-4 and ced-9. Ced-3 and ced-4 accelerate the process of apoptosis, while ced-9 prevents the course. A family of cysteine proteases with specificity for aspartic acid residues is reported to be mammalian homolog to ced-3, named as caspase. caspase-3, a member of caspase family, is activated in apoptosis of a multitude of cells, and always plays an important role in the signal pathway of apoptosis[3],[4]. A caspase-3-specific tetrapeptide inhibitor, Ac-DEVD-CHO, can abolish caspase-3-involved apoptosis[5]. Bcl-2 is a homolog of ced-9 in mammal. As a key regulator of the pathway of apoptosis, it is an anti-apoptosis member of this family[6-8].

Calcium is one of the most important intracellular signal elements in cells. Apoptosis induced by different factors differs in the dependence of calcium. It was reported that intracellular calcium could be transferred from cytoplast, especially from Golgi' $\mathrm{s}$ apparatus to nucleus in HT-induced apoptosis of HL-60 cells[9]. But the connection between intracellular calcium changes and signal pathway of apoptosis is unknown.

We reported in this paper on the effect of Bcl-2 protein and caspase-3 on calcium distribution in apoptosis of HL-60 cells. We found that activated caspase-3 can promote the movement of intracellular calcium from Golgi's apparatus to nucleus, and the process is inhibited by Ac-DEVD-CHO (inhibitor of caspase-3). Bcl-2 protein inhibits the movement and accumulation of intracellular calcium in nucleus because of its inhibition on caspase-3. Calcium relocalization taking place in apoptosis is irreversible, which is different from the intracellular calcium changes caused by growth factor.

\section{MATERIALS AND METHODS}

\section{Reagents}

HT was kindly provided by Professor Han Rui, Chinese Academy of Medical Sciences. Fluo3 AM, Hoechst 33342 and Enzchek ${ }^{T M}$ caspase-3 Assay kit\#2 were purchased from Molecular Probes. ECL Western Blot analysis kit were purchased from Amersham. Monoclonal antibody against Bcl-2 protein from Santa Cruz and DNA extraction kit from Dinguo Corporation.

\section{Cell culture}

The transfected human promyelocytic leukemia HL-60 / neo and HL-60/ bcl-2 cell lines were kindly provided by Dr. Wang Xiaodong (University of Texas Southwestern Medical Center, USA). Human acute myeloid leukemia (HL-60) cells were transfected with a retroviral vector containing a neomycin resistance gene ( neo cells), or the same vector containing a cDNA encoding human bcl-2 (bcl-2 cells). All cells were cultured with RPMI 1640 medium (Gibco) containing 10 $\%$ heat-inactivated fetal bovine serum in an atmosphere with $5 \% \mathrm{CO}_{2}$. 


\section{Overexpression of Bcl-2 protein identified by Western Blot}

Cells were collected and washed by cold PBS, resuspended in cell lysate (100M Tris HCl, $2.5 \%$ SDS, $10 \% \beta$-mercaptoethanol, $1 \mathrm{mM} \mathrm{PMSF}, 10 \%$ glycerol), and incubated on ice for $10 \mathrm{~min}$. After being broken by ultrasonic, cells were boiled for $2 \mathrm{~min}$. Then the lysate were centrifuged at $4^{\circ} \mathrm{C}$ for $10 \mathrm{~min}(14,000 \mathrm{~g})$, and the supernatants were subjected to $12 \%$ SDS-PAGE and then transferred onto a nitrocellulose filter. The filter was probed by mouse monoclonal antibody against Bcl-2, and the antigen-antibody complexes were visualized by an ECL method.

\section{DNA extraction and electrophoresis}

DNA were extracted from treated cells and analyzed by agarose gel electrophoresis as described in the reference of DNA extraction kit.

\section{Assay of caspase-3 activity}

Cells were collected and analyzed by Enzchek ${ }^{T M}$ caspase-3 Assay kit\#2, using HITACH F4010 fluorescence spectrophotometer $(496 \mathrm{~nm} / 520 \mathrm{~nm})$. This kit provides the substrate of caspase-3 ZDEVD-R110, which can be lysed by active caspase-3 and release R110, the fluorescence of which was analyzed by fluorescence spectro-photometer.

Staining HL-60 (neo)/(bcl-2) cells with Hoechst 33342 and Fluo-3 AM

Cells were collected and stained with $20 \mu \mathrm{M}$ Fluo-3 AM and $10 \mu \mathrm{M}$ Hoechst 33342 for $30 \mathrm{~min}$ at $37^{\circ} \mathrm{C}$. After washed for more than 3 times, cell were resuspended by RPIM $1640+10 \%$ FCS. Stained cells were observed by fluorescence microscope.

\section{Intracellular calcium distribution observed by laser scanning confo- cal microscopy (LSCM)}

Cells were observed by LEICA PCS-NT laser scanning confocal microscopy (LSCM) after being stained with Fluo-3 AM and treated with drugs. Excitation at $488 \mathrm{~nm}$, emission at $530 \pm 30 \mathrm{~nm}$.

\section{RESULTS}

\section{The inhibition of HT-induced apoptosis in HL60 cells by Bcl-2 protein}

When the expression of Bcl-2 protein was compared in two cell lines used in this experiment, it was found that HL-60 ( bcl-2) cells contained about 20 fold more protein than HL-60 ( neo) cells (Fig 1).

Now, if HT ( $1 \mu \mathrm{g} / \mathrm{ml})$ was applied to these cells, only HL-60( neo) cells, but not HL-60 ( bcl-2) cells, can be induced to undergo apoptosis, which is characterized by chromatin condensation and DNA fragmentation. The results suggest that overexpressed Bcl-2 protein in HL60 ( bcl-2) cells can inhibit HT-induced apoptosis (Fig 2).

At the same time, activity of caspase-3 was analyzed by Enzchek ${ }^{T M}$ caspase-3 Assay kit\#2 as mentioned in Materials and methods. It was found that caspase-3 was activated during HT-induced apoptosis, and the elevation of caspase-3 activity in HL-60( neo) cells was totally inhibited in HL-60 ( bcl-2) cells. Thus, Bcl-2 protein could inhibit the activation of caspase-3 (Fig 3). 
Effect of Bcl-2 and caspase-3 on calcium distribution in apoptosis of HL-60 cell

$k D$

$26 k D$

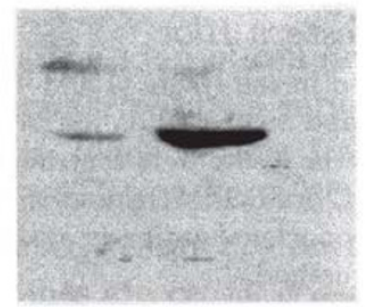

12

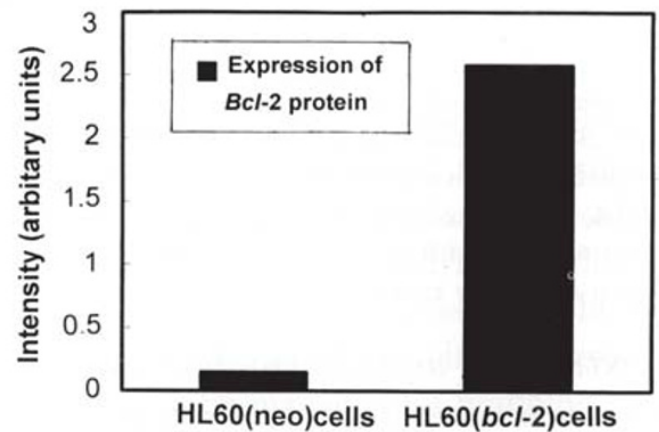

HL60(neo)cells HL60(bcl-2)cells

Fig 1. Expression of Bcl-2 protein in HL-60 ( neo/ bcl-2) cells 1. HL-60 ( neo) cells 2. HL-60 ( bcl-2) cells
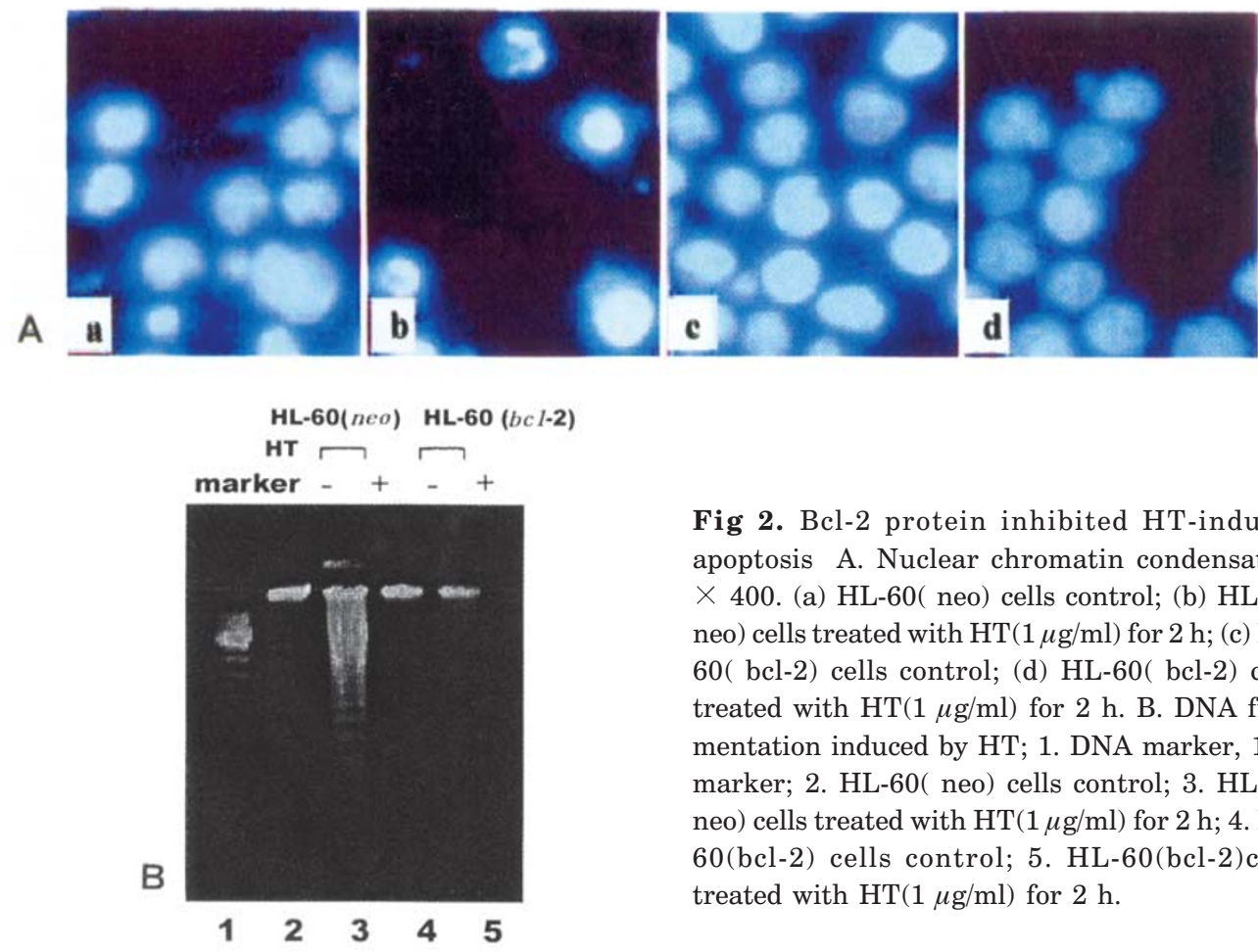

Fig 2. Bcl-2 protein inhibited HT-induced apoptosis A. Nuclear chromatin condensation $\times$ 400. (a) HL-60 ( neo) cells control; (b) HL-60( neo) cells treated with $\mathrm{HT}(1 \mu \mathrm{g} / \mathrm{ml})$ for $2 \mathrm{~h}$; (c) HL60( bcl-2) cells control; (d) HL-60( bcl-2) cells treated with $\mathrm{HT}(1 \mu \mathrm{g} / \mathrm{ml})$ for $2 \mathrm{~h}$. B. DNA fragmentation induced by HT; 1 . DNA marker, $1 \mathrm{~kb}$ marker; 2. HL-60( neo) cells control; 3. HL-60( neo) cells treated with $\mathrm{HT}(1 \mu \mathrm{g} / \mathrm{ml})$ for $2 \mathrm{~h} ; 4$. HL60(bcl-2) cells control; 5. HL-60(bcl-2) cells treated with $\mathrm{HT}(1 \mu \mathrm{g} / \mathrm{ml})$ for $2 \mathrm{~h}$.

$\triangleright$ Fig 4. A-E. Redistribution of intracellular calcium during HT-induced apoptosis in Hl-60 (neo/ bcl-2) cells; its inhibition by Bcl-2 protein and caspase- 3 inhibitor Note that the highest $\left[\mathrm{Ca}^{2+}\right] \mathrm{i}$ is found in the perinuclear region (Golgi apparatus, area 1). Cell nucleus (area 2) and the rest areas of the cytosol (area 3) showed a very low $\left[\mathrm{Ca}^{2+}\right] i$.A. HL-60 ( neo) control cells; B. HL-60 ( neo) control cells treated with HT (1mg/ml) for 2 h; C. HL-60 ( bcl-2) control cells; D. HL-60 ( bcl-2) cells treated with HT (1mg/ml) for $2 \mathrm{~h}$; ,b. E. HL-60 ( neo) cells pretreated with Ac-DEVD-CHO (100 m M for 1 $\mathrm{h}$ and then treated with $\mathrm{HT}(1 \mathrm{mg} / \mathrm{ml})$ for $2 \mathrm{~h}$; a. stained with $10 \mu \mathrm{M}$ Hoechst $33342 \times 400$; b. stained with $20 \mu$ M Fluo-3 AM $\times 400$; c. stained with Fluo-3 AM and visualized by LSCM. 
Zhang M, HQ Zhang,SB Xue

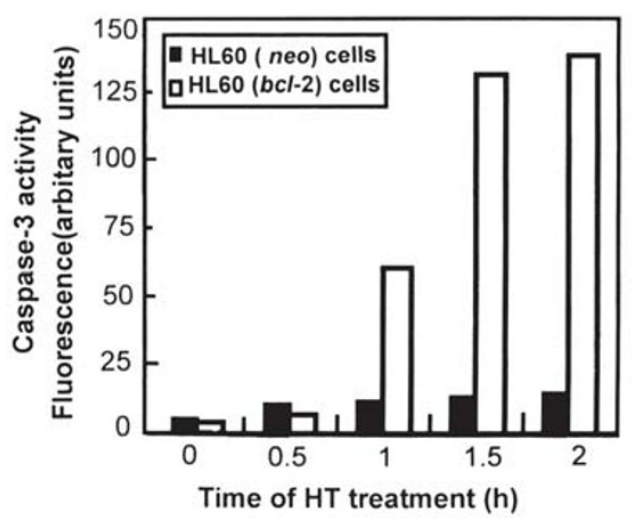

The change of intracellular calcium distribution in HT-induced apoptosis and its relation to caspase-3

Intracellular calcium accumulated mostly in the peri-nuclear area (i.e.Golgi apparatus) in control HL-60 ( neo) cells[10], while cell nucleus showed a distinctly lower $\left[\mathrm{Ca}^{2+}\right] \mathrm{i}$ than peri-nuclear region and other areas of cytoplasm (Fig 4A). However, HL-60 ( neo) cells treated with HT present a very different pattern of Fluo-3 AM staining. Labeling of

Fig 3. Bcl-2 protein inhibited the activation of caspase-3

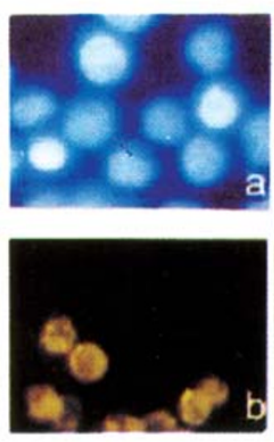

A

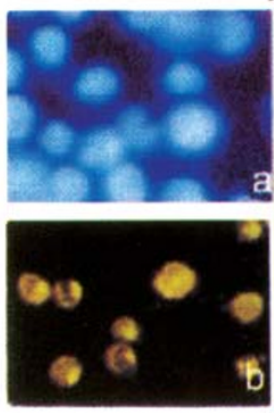

C

E
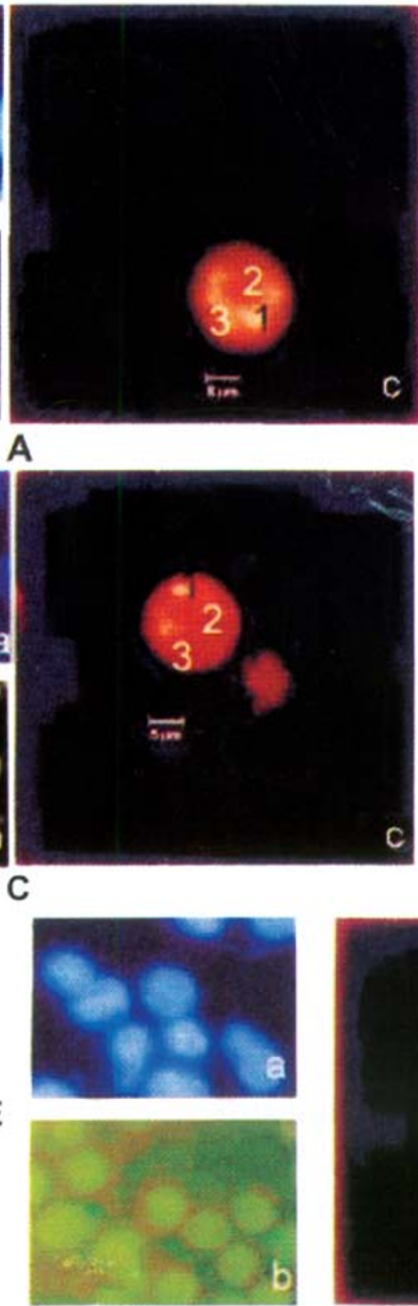
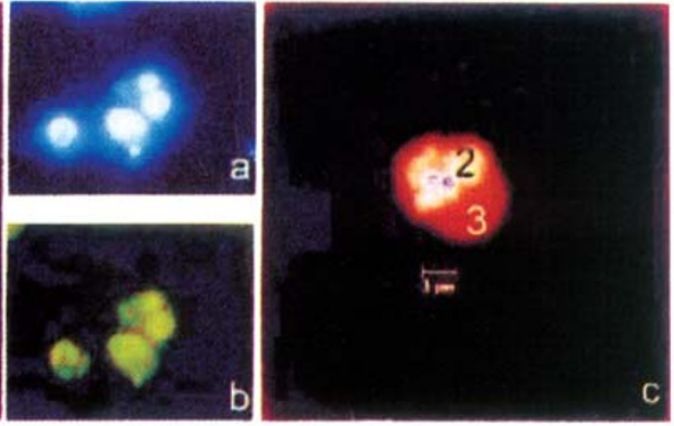

B
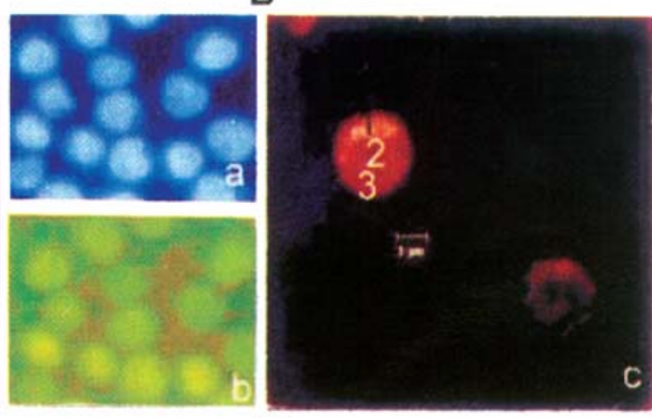

D

$-255$

$-128$

E

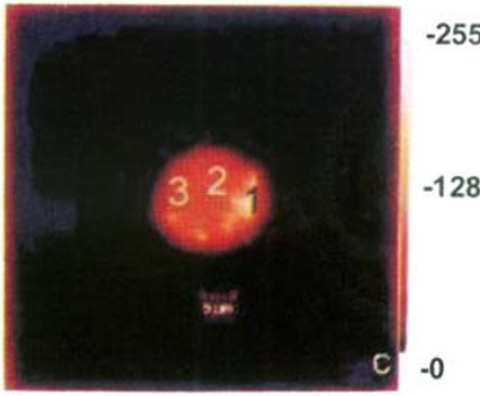


Effect of Bcl-2 and caspase-3 on calcium distribution in apoptosis of HL-60 cell

intracellular $\mathrm{Ca}^{2+}$ and chromatin revealed the accumulation of calcium in the nuclear region (Fig 4B, compare with A). These results suggest that in apoptotic HL-60 ( neo) cell intracellular calcium accumulated in the nucleus due to the release of calcium from the peri-nuclear area and relocalized in area of chromatin condensation (i.e. nuclear region).

But intracellular calcium relocalization was not observed in HL-60 ( bcl-2) cells after their being treated with HT. In these cells, Intracellular calcium showed predominantly higher calcium accumulation in the peri-nuclear area (Fig $4 \mathrm{D}$, compare with C). These results indicated that overexpressed Bcl-2 protein could prevent this calcium redistribution induced by HT. (Fig 4C, D, )

However, the above intracellular calcium relocalization was not observed in Ac-DEVDCHO treated HL-60 ( bcl-2) cells after their being treated with HT, a fact which indicated that inhibitor of caspase-3 can prevent such calcium translocation (Fig 4E).

\section{DISCUSSTION}

In spite of the recent progress in studies on the mechanism of apoptosis, it is still unclear the relationship between calcium and signal pathway of apoptosis. There are calcium changes during apoptosis: (1) Enhanced $\mathrm{Ca}^{2+}$ influx. McConkey showed that intracellular free calcium increased in glucocorticoid-stimulated apoptosis and EGTA inhibited $\mathrm{Ca}^{2+}$ increase and apoptosis[11]. (2) Intracellular calcium released from calcium store. For example, thapsigargin (TG), inhibitor of endoplasmic reticulum (ER) $\mathrm{Ca}^{2+}$ ATPase, can induce apoptosis in neuroplastoma cells through the increase of $\left[\mathrm{Ca}^{+}\right]_{I}[12]$. (3) $\left[\mathrm{Ca}^{2+}\right]$ in mitochondria varies in apoptosis. When neural cell was induced by staurosporine, $\left[\mathrm{Ca}^{2+}\right]$ increased in cytosol first, and then it was accompanied with $\left[\mathrm{Ca}^{2+} \mathrm{z}\right]$ increase in mitochondria[13]. (4) Intracellular calcium relocalization. We have reported that free $\left[\mathrm{Ca}^{2+}\right] \mathrm{i}$ do not change much in HT-induced apoptosis of HL-60 cells. However, intracellular calcium relocalized. Intracellular calcium transfers from cytoplast, especially from Golgi's apparatus to nucleus in this kind of apoptosis[9], which was the first work to demonstrate relocalization of intracellular calcium at the final stage of apoptosis. Others also reported that $\mathrm{Ca}^{2+}$ pool in the endoplasmic reticulum was depleted in a lymphoid cell line in response to glucocorticoid treatment[14], suggesting that intracellular $\mathrm{Ca}^{2+}$ storage sites appeared to be affected.

In the above-mentioned cases of apoptosis, it seems clear that the source of calcium for its increase or change in distribution may be derived either from $\mathrm{Ca}^{2+}$ influx from outside or released from intracellular calcium store. However, both the increase of $\left[\mathrm{Ca}^{2+}\right] \mathrm{i}$ and $\mathrm{Ca}^{2+}$ accumulation in nucleus can bring forth the increased activity of various protease[15] and nuclease[16]. Activation of $\mathrm{Ca}^{2+}$-dependent protein kinases calpain, and/or phosphatases leading to alterations in gene transcription is one way which $\mathrm{Ca}^{2+}$ might regulate apoptosis. As an example, cyclosporin A, an immunosuppressant, can block $\mathrm{Ca}^{2+}$ dependent apoptosis in lymphoid model systems[17], indicating that calcineurin activa- 
tion may be required for these responses. However, researchers seldom establish relationship between $\mathrm{Ca}^{2+}$ storage sites and protease activation.

On the basis of our previous finding of calcium relocalization in HT-induced apoptosis of HL-60 cells, the present results shows that the activity of caspase-3 is enhanced in HTinduced apoptosis in HL60 cells, and Bcl-2 protein can inhibit the apoptosis and the activation of caspase-3. Furthermore, Bcl-2 protein and Inhibitor of caspase-3 can prevent the relocalization of intracellular calcium in HT-induced apoptosis. These reasults lead us to draw a conclusion that caspase-3, one of the most important caspases in signal pathway in apoptosis, can promote, at least in our present system, the movement of intracellular calcium from Golgi's apparatus to nucleus, and the process can be inhibited by Ac-DEVD-CHO, inhibitor of caspase-3. Increased $\left[\mathrm{Ca}^{2+}\right]$ in nucleus is potentially related to the activation of $\mathrm{Ca}^{2+}$ dependent endonuclease, chromatin condensation and DNA fragmentation. Bcl-2 protein can inhibit the movement of intracellular calcium and its accumulation in nucleus via its inhibition on caspase-3.

Earlier in our study with human fibroblasts (2BS) cells, we have found that $\mathrm{Ca}^{2+}$ which accumulated in Golgi' s apparatus as intracellular store in control cells, could be released and accumulated in nucleus following their treatment with PDGF, but became re-accumulates in Golgi's apparatus 3 minutes later[10]. The change of calcium location in HT-induced apoptosis of HL-60 cells differs from the above physiological event in its irreversibleness of intracellular calcium releasing from Golgi apparatus and accumulating in the nucleus. Recent work from Kruman et al. also showed that: NGF can resume the concentration of $\left[\mathrm{Ca}^{2+}\right] \mathrm{i}$ and inhibit apoptosis in PC12 cells[18]. Exposure of cultured PC12 cells to staurosporine resulted in a rapid and prolonged elevation of intracellular free calcium levels $\left[\mathrm{Ca}^{2+}\right]$ i, with calcium level elevating in nucleus. Treatment of cells with nerve growth factor within 1-2 $\mathrm{h}$ of staurosporine exposure resulted in the recovery of $\left[\mathrm{Ca}^{2+}\right] \mathrm{i}$ and nuclear calcium to normal levels, leading to the inhibition of apoptosis, thus supporting the contention that the irreversiblity of $\mathrm{Ca}^{2+}$ translocation is an important event in apoptosis.

\section{ACKNOWLEDGEMENT}

We thank Dr. WANG Xiao Dong (University of Texas Southwestern Medical Center, USA) for his advice and help. We thank Professor LI Shu Wen for her kindly help. Project supported by the National Natural Science Foundation of China (Grant No. 39730160).

\section{REFERENCES}

[1] White E. Life, death and pursuit of apoptosis Genes Dev 1996; 10:1-15.

[2] Wyllie AH. glucocorticoid induced thymocyte apoptosis is associated with endogeneous endonuclease activation. Nature 1980; 284:555-6.

[3] Yuan JY, Shaham S, Ledoux S, Ellis MH, Horvitz RH. The C. elegans cell death gene ced-3 encodes a protein similar to mammalian interleukin-1b converting enzyme. Cell 1993; 75:641-52.

[4] Alnemri ES, Livingston DJ, Nichoison DW, Salvesen G, Thornberry NA, Wong WW. Human ICE/CED- 
Effect of Bcl-2 and caspase-3 on calcium distribution in apoptosis of HL-60 cell

3 protease nomenclature. Cell 1996; 87:171.

[5] Nicholson WD, Ali A, Thornberry NA, et al. Identification and inhibition of the ICE/CED-3 protease necessary for mammalian apoptosis. Nature 1995; 376:37-43.

[6] Ibrado AM, Huang Y, Fang G, Liu L, Bhalla K. Overexpression of Bcl-2 or Bcl-XL inhibits Ara-C-induced CPP32/Yama protease activity and apoptosis of human acute myelogenous leukemia HL-60 cells. Cancer Res. 1996; 56:4743-8.

[7] Armstrong RC, Aja T, Xiang J, Gaur S, Krebs JF, Hoang K, Bai X, Korsmeyer SJ, Karanewsky DS, Fritz LC, Tomaselli KJ. Fas-induced activation of the cell death-related protease CPP32 is inhibited by Bcl-2 and by ICE family protease inhibitors. J Biol Chem 1996; 271:16850-5.

[8] Chinnaiyan AM, Orth K, O'rourke K, Duan H, Poirier GG, dixit BM. Molecular ordering of the cell death pathway. Bcl-2 and Bcl-xL function upstream of the CED-3 like apoptotic proteases. J Biol Chem 1996; 271:4573-6.

[9] Fang M, Zhang HQ, Xue SB, et al. Intracellular calcium distribution in apoptosis of HL-60 cells induced by harringtonine: intranuclear accumulation and regionalization. Cancer Lett 1998; 127(1-2):113-21.

[10] Cui J, Yan L, Shaobai Xue. Visualization of Golgia apparatus as an intracellular calcium store by laser scanning confocal microscope. Cell Res 1995; 5:165-79.

[11] McConkey DJ Orrenius S. The role of calcium in the regulation of apoptosis. J Leukocyte Biol 1996; 59:775-83.

[12] Nath R, Raser KJ, Hajimohammadreza I, Wang KKW. Thapsigargin induces apoptosis in SH-SY5Y neuroplastoma cells and cerebrocortical cultures. Biochem Mol Int 1997; 43(1):197-205.

[13] Kruman II, Mattson MP. Pivotal role of mitochondria calcium uptake in neural cell apoptosis and necrosis. J Neurochem 1999; 72(2):529-40.

[14] Lam M, Dubyak G, distelhorst XW. Effect of glucocorticoid treatment on intracellular calcium homeostasis in mouse lymphoma cells. Mol Endocrinol 1993; 269:365-70.

[15] Chakraborti T, Ghosh SK, Michael JR, Batabyal SK, Chakraborti S. Mol. Targets of oxidative stress in cardiovascular system. Cell Biochem 1998; 187(1-2):1-10.

[16] Walker PR, Sikorska m. New aspects of the mechanism of DNA fragmentation in apoptosis. Biolchem Cell biol 1997; 75(4):287-99.

[17] Makrigiannis AP, Hoskin SW. Cyclosporin A inhibits 2-chloroadenosine-induced DNA cleavage in mouse thymocytes.Int J Immunopharmacol 1994; 16:995-1001.

[18] Kruman I, Guo Q, Mattson MP. Calcium and reactive oxygen species mediate staurosporine-induced mitochondria dysfunction and apoptosis in PC12 cells. J Neurosci Res 1998; 51(3):293-308.

Received April-9-2000. Revised Aug-9-2000. Accepted Aug-15-2000. 